\title{
Correction to: Behavior-analytic intervention for women with fibromyalgia and insomnia: a single subject design
}

Luziane de Fátima Kirchner ${ }^{1,2^{*}}$ and Maria de Jesus Dutra dos Reis ${ }^{1,3}$

\section{Correction to: Psicol Refl Crít 34, 5 (2021) \\ https://doi.org/10.1186/s41155-020-00169-2}

Following the publication of the original article (de Fátima Kirchner \& de Jesus Dutra dos Reis, 2021), the authors identified typesetting errors in Figs. 2 and 3. The correct figures are given below, and the original article has been corrected.

\section{Author details}

'Federal Univerisity of São Carlos-UFSCar, KM 235 Washington Luis, São Carlos and São Paulo 13565-905, Brazil. ${ }^{2}$ Dom Bosco Catholic UniversityUCDB, 6000 Tamandaré Avenue, Jardim Seminário, Campo Grande and Mato

Grosso do Sul 79117-900, Brazil. 'University of São Paulo, São Paulo, Brazil.

Published online: 11 March 2021

\section{Reference}

de Fátima Kirchner, L., \& de Jesus Dutra dos Reis, M. (2021). Behavior-analytic intervention for women with fibromyalgia and insomnia: a single subject design. Psicologia: Reflexão e Crítica, 34, 5. https://doi.org/10.1186/s41155-02000169-2.

\footnotetext{
The original article can be found online at https://doi.org/10.1186/s41155020-00169-2.

*Correspondence: luzianefk@gmail.com

${ }^{1}$ Federal Univerisity of São Carlos-UFSCar, KM 235 Washington Luis, São Carlos and São Paulo 13565-905, Brazil

${ }^{2}$ Dom Bosco Catholic University- UCDB, 6000 Tamandaré Avenue, Jardim

Seminário, Campo Grande and Mato Grosso do Sul 79117-900, Brazil

Full list of author information is available at the end of the article
}

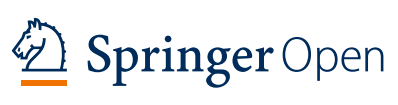

(c) The Author(s). 2021 Open Access This article is licensed under a Creative Commons Attribution 4.0 International License which permits use sharing, adaptation, distribution and reproduction in any medium or format, as long as you give appropriate credit to the original author(s) and the source, provide a link to the Creative Commons licence, and indicate if changes were made. The images or other third party material in this article are included in the article's Creative Commons licence, unless indicated otherwise in a credit line to the material. If material is not included in the article's Creative Commons licence and your intended use is not permitted by statutory regulation or exceeds the permitted use, you will need to obtain permission directly from the copyright holder. To view a copy of this licence, visit http://creativecommons.org/licenses/by/4.0/. 


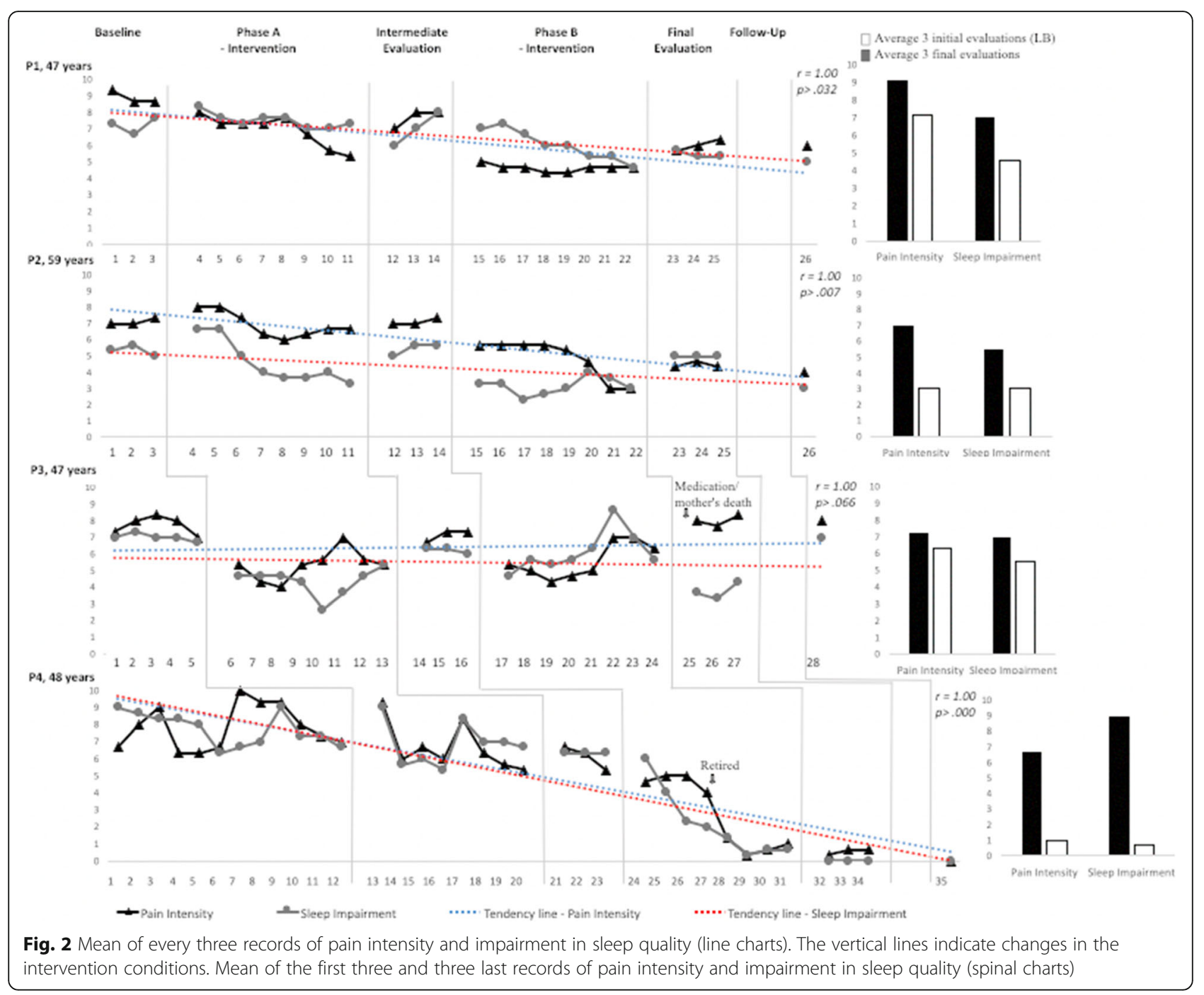




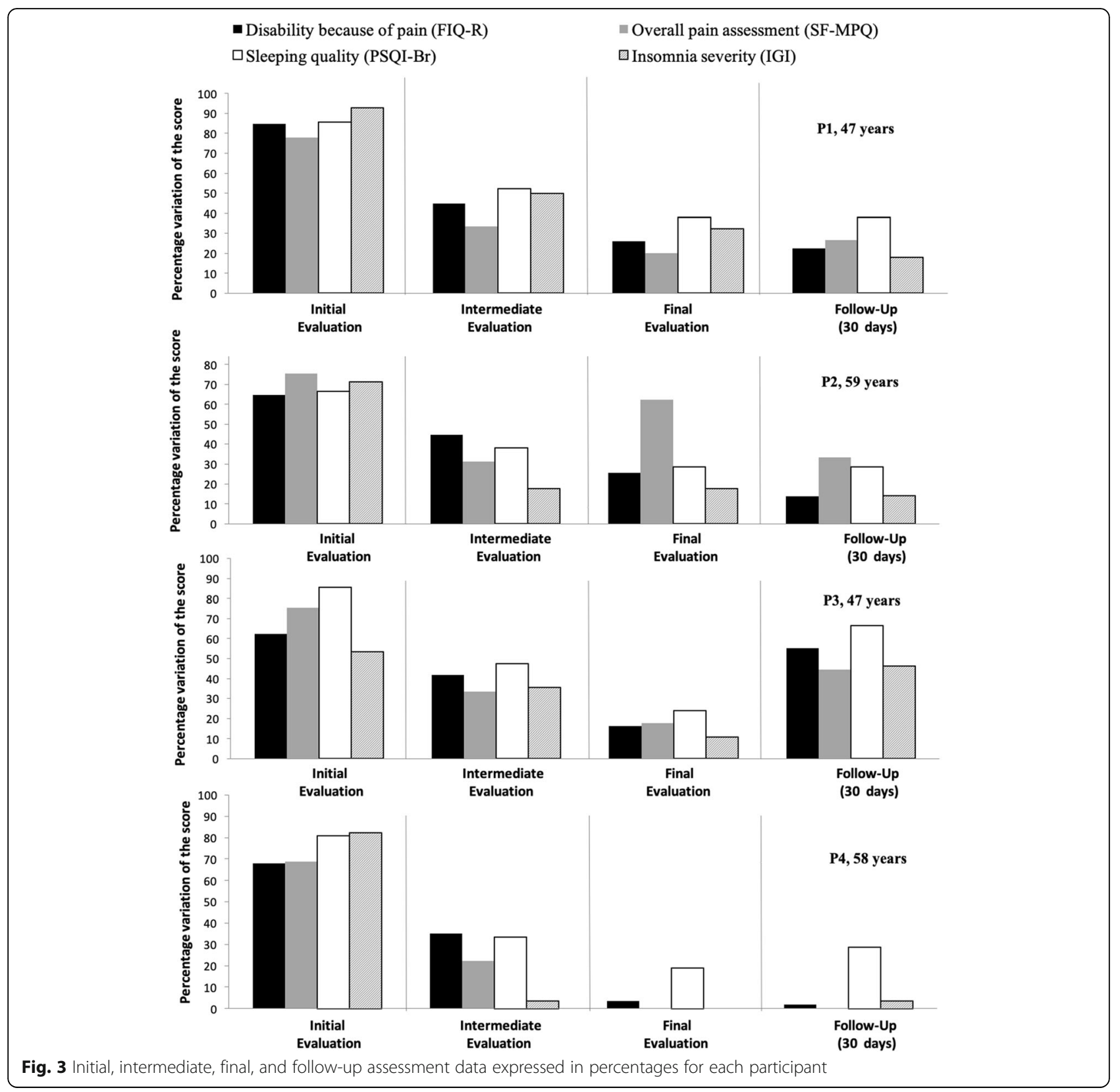

